\title{
Physical Exam Method
}

National Cancer Institute

\section{Source}

National Cancer Institute. Physical Exam Method. NCI Thesaurus. Code C113375.

A systematic course of action that is performed in order to complete a physical examination. 